\title{
Paleomagnetisation of Kimberlites on the BHP/Dia Met Diamond Project
}

\author{
St. Pierre, M. ${ }^{1}$, Wynne P.J. ${ }^{2}$ and Counts, B. ${ }^{3}$
}

1. BHP Minerals Canada Ltd., Diamond Exploration, Kelowna, B.C., Canada.

2. Pacific Geoscience Center, Sidney, B.C., Canada.

3. LithoQuest International Mineral Exploration Services, Kelowna, B.C., Canada.

\section{Introduction}

The BHP/Dia Met kimberlites are located in the central portion of the Slave tectonic province in the Northwest Territories of Canada. A number of techniques have been tried to determine emplacement ages of the kimberlites, including $\mathrm{Rb}-\mathrm{Sr}$ on phlogopite and $\mathrm{U}-\mathrm{Pb}$ on perovskite and zircon. Major limitations on these methods include a paucity of datable phlogopite and zircon, and very small grain size of perovskite. Fossils collected from 13 kimberlites have constrained the ages to Late Cretaceous/Early Tertiary.

Strong magnetic remanence contributes to the magnetic expression of many kimberlites in the project area. Both normal and reversed remanences are observed and imply different emplacement ages. On this basis, dating was attempted by measuring the paleomagnetic characteristics of kimberlites, and comparing the results to reconstructed polar drift and reversals through time. The measurements were expected to constrain the emplacement ages to within 10 million years. The principles, laboratory procedures and results of a paleomagnetic study carried out on eight BHP/Dia Met kimberlites are presented.

\section{Paleomagnetism}

When rocks form they can acquire a magnetisation related to the Earth's magnetic field present at the time. This is referred to as the rocks primary remanent magnetisation and can happen in igneous rock when it cools to below its magnetic minerals critical Curie temperature (thermoremanent magnetisation), or in sedimentary rocks when the magnetic minerals settle out of suspension (depositional remanent magnetisation). The rock therefore retains a memory of the direction of Earth's magnetic field present at the time of its formation. In the BHP/Dia Met kimberlites the primary remanent magnetisation is dominated by thermoremanent magnetisation. A ferrimagnetic mineral such as magnetite, which is by far the most important magnetic mineral in the BHP/Dia Met kimberlites, exhibits spontaneous magnetisation parallel to the field in which it formed.

Continents and the geomagnetic pole have moved relative to each other over time and as a consequence the inclination observed at a given site varies over time. To estimate age, comparisons can be made between inclinations derived from available Mesozoic and Cenozoic cratonic reference paleopoles of North America and inclinations measured in the kimberlite specimens. The record of paleomagnetic reversals of the Earth's magnetic field combined with a measurement of the specimen's remanent magnetisation direction (normal or reversed), can in some cases enhance the age estimates derived from inclination measurements.

\section{Sampling and Sample Preparation}

Eight vertical drill holes with competent, unsplit sections were subsampled. Three adjacent lengths of core were collected with the up-hole direction carefully recorded. From these 110 lengths of 
core 177, right cylinder specimens were cut. The vertical axis and way up on the cores was preserved in the preparation of the specimens. The direction of magnetisation (declination and inclination), intensity of magnetisation (Natural Remanent Magnetisation or NRM) and susceptibility of each specimen were measured. Using the NRM intensity and the susceptibility measurements, the Koeninsberger ratio for each specimen was calculated. Each specimen was then incrementally demagnetised using either alternating field or thermal methods and remeasured after each treatment step. The mean magnetisation for each specimen was calculated. The declinations measured for these specimens are meaningless because the cores were unoriented about the vertical axis. The mean inclinations (I) are summarised in Table 1, with $\mathrm{N}$ representing the number of samples, $\mathrm{CI}$ the error envelope for a $95 \%$ confidence, and $\mathrm{K}$ the precision of the mean (a higher $\mathrm{K}$ value means less scatter). Positive (negative) inclinations denote magnetisation acquired during normal (reversed) polarity chrons.

Table 1. Average inclination for drill hole samples taken from various kimberlites.

\begin{tabular}{|c|c|c|c|c|}
\hline Koala & 61 & 65.8 & $\begin{array}{c}\text { 16.8 } \\
-4.4\end{array}$ & 16 \\
\hline Beaver & 17 & -78.0 & \pm 1.2 & 491 \\
\hline Jay & 5 & -29.8 & +19.6 & -39.8 \\
& & & +5.5 & 7 \\
\hline Caribou & 4 & 72.3 & -4.3 & 67 \\
\hline Kaska & 4 & -79.7 & \pm 2.9 & 375 \\
\hline Misery & 14 & -73.6 & +4.3 & 87 \\
& & & -8.8 & 11 \\
\hline LS-2 & 6 & -74.8 & +12.5 & 671 \\
\hline Koala West & 8 & -73.6 & \pm 1.5 & \\
\hline
\end{tabular}

\section{Laboratory Results}

Two of the eight holes have normal magnetisation (positive inclinations), and the remainder are reversed. One of the pipes with normal magnetisation (Caribou) has too few specimens to adequately define an age. The other pipe with normal magnetisation (Koala) is a very poor recorder of the paleomagnetic field due to low susceptibility and the predominance of crater facies material, which is formed in a cool and easily deformed environment. The reversed magnetisation of the other pipes precludes their emplacement from 124 to $83 \mathrm{Ma}$, a time period when the Earth's magnetic field was monotonously normal. The reversely magnetised pipes must either predate or postdate the "Long Cretaceous Normal".

In Figure 1 the mean inclination, derived from the Beaver kimberlite samples and presented in Table 1, is plotted on the Apparent Polar Wander Path inclination curve (Besse and Courtillot, 1991), calculated for the location of the BHP/Dia Met kimberlites. Note that between Early Tertiary $(60 \mathrm{Ma})$ and present the reference field inclination varies by only about 2.4 degrees. This restricted range is not sufficient to achieve age resolution of $10 \mathrm{Ma}$, which was initially anticipated. The Beaver samples, based on their mean inclination are either $130 \mathrm{Ma}$ or $60 \mathrm{Ma}$ in age, the latter is in better agreement with ages arrived at by other means. The similarity in inclination and identical Koeninsberger ratios between the Kaska and Beaver kimberlite samples suggests a cogenetic source. 


\section{Beaver Mean Inclination $=\mathbf{- 7 8 . 0}$ $N=17, k=491$}

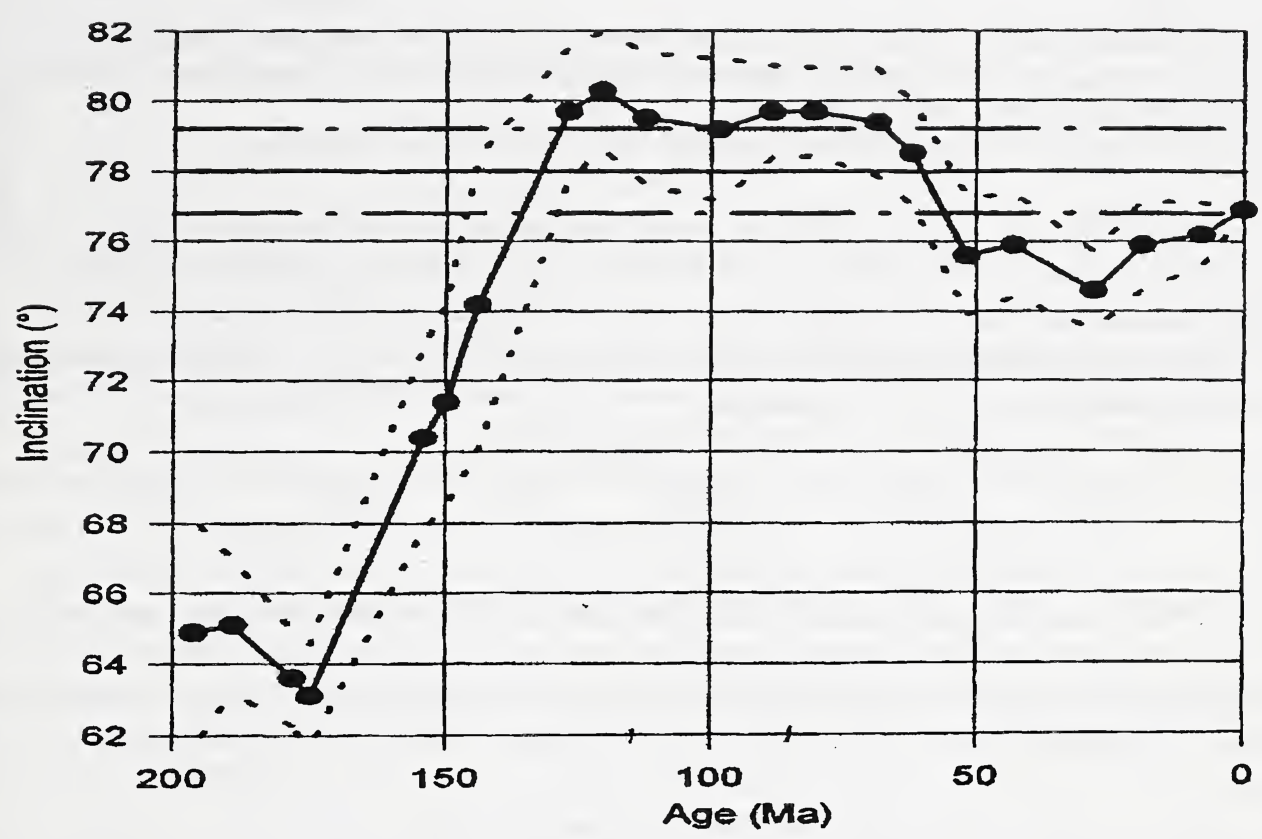

Besse and Courtillot (1991) APWP BHP drill hole

Figure 1. Plot of the change in the inclination over the BHP/Dia Met property combined with the Mean inclination and $\mathrm{CI}$ error for the Beaver kimberlite samples.

\section{Conclusions}

The expected result of constraining BHP/Dia Met kimberlite ages to $10 \mathrm{Ma}$ through the use of paleomagnetic remanence measurements proved to be too optimistic. This is primarily due to the limited change in the inclination of the paleomagnetic pole during the period surrounding the kimberlites emplacement, which from various dating methods has been determined to be about 60 Ma. BHP/Dia Met project area kimberlite emplacement ages less than $140 \mathrm{Ma}$ will generally have more than one possible age according to paleomagnetic remanence inclination measurements. Cogenetic relationship between intrusive suites may be derived through magnetic similarities, such as the ones observed between the Beaver and Kaska kimberlites.

\section{References:}

Besse, J. And V, Courtillot. Revised and synthetic apparent polar wander paths of the African, Eurasian, North American and Indian plates, and true polar wander since $200 \mathrm{Ma}$; Journal of Geophysical Research, 96, p. 4029-4050, 1991. 